\title{
A mentira verdadeira do teatro vs. a verdade mentirosa da vida
}

\author{
Sebastiana Fadda
}

Titulo: Esta noite improvisa-se (Questa sera si recita a soggetto,1930). Autor: Luigi Pirandello. Tradução: J. A. Osório Mateus e Luis Miguel Cintra. Encenação: Jorge Silva Melo. Assistentes de encenação: João Miguel Rodrigues e Luis Godinho. Cenografia e figurinos: Rita Lopes Alves. Luz: Pedro Domingos. Direcção musical: Rui Rebelo. Interpretação: António Simão, Pedro Lacerda, Cândido Ferreira, Lia Gama, Silvia Filipe, Sara Belo, Andreia Bento, Cecilia Henriques, João Meireles, Alexandre Ferreira, John Romão / Luís Godinho, Victor Gonçalves, Pedro Luzindo, Miguel Telmo, Alexandra Viveiros, João Miguel Rodrigues, Joaquim Pedro, Carlos Marques, Luis Godinho / Pedro Carraça, António Rodrigues, Jéssica Anne, João Abel, Miguel Aguiar, Ricardo Batista, Sara Moura e Vânia Rodrigues. Músicos: António Pedro, João Cabrita / Elmano Coelho, Miguel Tapada e Vitor llhéu. Produção: Artistas Unidos e Teatro Nacional D. Maria II. Local e data de estreia: Sala Garrett, Teatro Nacional D. Maria II, Lisboa, 5 de Março de 2009.

É oportuna e necessária a formulação das questões levantadas pela nova direcção do Teatro Nacional D. Maria II acerca das funções que deveria exercer um Teatro Nacional, bem como dos objectivos que deveria alcançar para estar à altura dos propósitos pelos quais foi criado e acolher os impulsos plurais da contemporaneidade (AA.W. 2009: 8-13). E foi um sinal extremamente significativo - ou um saudável sintoma de uma prática democrática actuante - 0 alargamento do diálogo aos cidadãos e aos profissionais ligados às artes do espectáculo, proporcionado pelo encontro que decorreu no dia 27 de Março num Salão Nobre repleto e heterogéneo, inclusive nas posições que animaram o debate. Em breve, a seguir à conferência de Stephen Wilmer, que falou sobre a organização dos teatros nacionais nos vários paises da Europa, na audiência expressou-se o anseio por um teatro nacional que não seja nacionalista, pela preservação da memória histórica que está na origem do presente, pela abertura às várias contaminações e instâncias criativas nacionais e internacionais, por uma maior integração e presença do teatro na vida da cidade.

Fruto, muito provavelmente, mais da vontade do que do acaso, como emblemático complemento para dar corpo visivel às interrogações e reflexões que o Teatro Nacional coloca a si próprio e à cidade, a peça em cena nessa altura na Sala Garrett, e que marcou a reabertura do D. Maria II, era Esta noite improvisa-se, uma das obras-primas do teatro de Luigi Pirandello e sintese da famosa trilogia do "teatro no teatro" - começada com Sei personaggi in cerca d'autore e prosseguida com Ciascuno a suo modo - (Romei 1993), que soube pôr em causa e questionar produtivamente o teatro do seu tempo. E, se necessário fosse, o espectáculo demonstrou que a Arte não tem nacionalidade nem precisa de passaporte, porque tem cidadania na vida de quem a faz, aprecia e dela desfruta. Salientou, também, a importância da interrogação e da dúvida, da força propulsora que estas têm para transformar o quotidiano a partir, porque não, do objecto artístico, lançando as bases para a redescoberta e a recriação do já conhecido, mas podendo levar mais longe a reflexão que propõe.

É que este espectáculo chegou mesmo muito mais longe do que o texto deixaria supor, porque a encenação de Jorge Silva Melo não foi, nem nunca podia ser, de cunho museológico. Houve uma apropriação do texto que, não deixando de ser de Pirandello, criou outro texto - cénico é óbvio - feito duma mistura de passado remoto, passado próximo e presente, e ainda, de italianidade, sicilianidade portugalidade e "artistasunidade", como bem notou, usando outras palavras, Rui Pina Coelho (Coelho 2009: 9). Muitas "idades", portanto, a que é obrigatório acrescentar outra: a cumplicidade. 0 que gerou um prazer palpável do jogo e uma proliferação espantosa de subentendidos. Porque Jorge Silva Melo conhece demasiado bem a cultura italiana para perder a oportunidade de libertar o seu gosto do lúdico, semeando algumas das suas inúmeras referências, conhecimentos e saberes, respeitando o autor e aplicando autonomia, sendo-lhe fiel e irreverente, estabelecendo com ele uma comunicação feita de intertextualidades, ou antes talvez de "intercenicidades", pondo o passado (a história do teatro) a interpelar não só o passado (a história do espectáculo no sentido mais lato), como o presente (o teatro português e os elementos fundadores duma companhia).

Em primeiro lugar, lembre-se que o encenador fez parte, juntamente com J.A. Osório Mateus e Luis Miguel Cintra (eximios tradutores da peça em análise) da direcção daquela fabulosa colecção de teatro que a Editorial Estampa lançou no mercado no início dos anos 70. A tradução era antecedida de um prefácio, não assinado, onde se esclareciam os termos do "teatro no teatro", da irrupção do discurso metateatral na obra dramática pirandelliana, da pulverização do elemento narrativo tradicional na estrutura dramatúrgica da peça, da desconstrução da ficção para questionar os mecanismos que regem o teatro e a (sua) realidade (Pirandello 1974: 7-21). Ai utilizavase com frequência o termo gideano "mise en abîme" para 


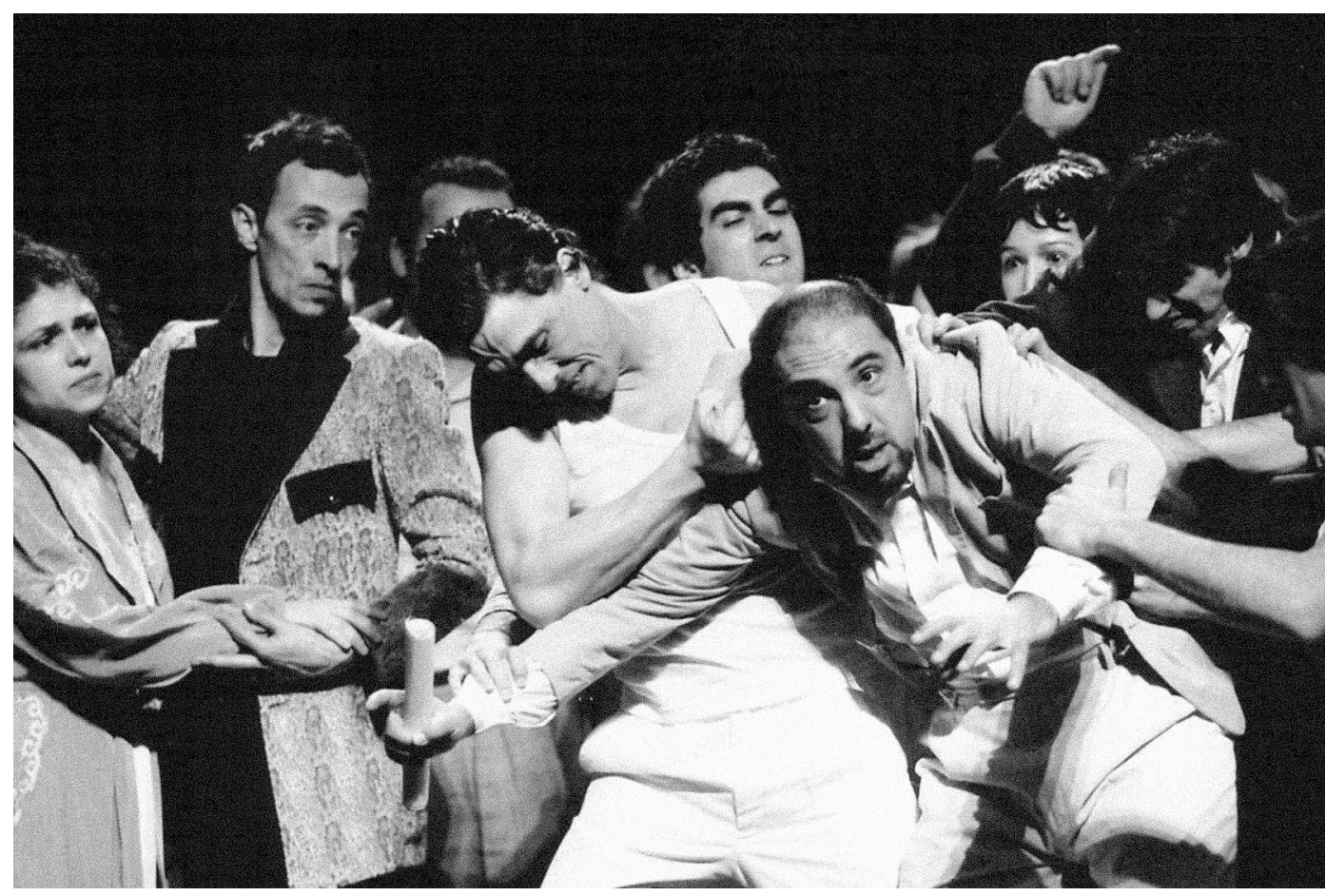

comentar os processos utilizados pelo dramaturgo para a sua desmontagem, que não se limitava a pôr em cena um encenador na fase de construção dum espectáculo (recurso básico a que tem sido reduzida a poética da cena pirandelliana, descaindo no "pirandellismo"). Havia muitissimo mais, porque a mise en abîme em Esta noite improvisa-se é contínua, acontece a vários niveis e inclui o conceito germinal de contaminação das artes do palco tão em voga nos nossos dias.

Uma fuga aos ditames do autor é praticada logo no inicio, quando os actores que personificam os espectadores são colocados no proscénio e no palco a olharem para a moldura dum teatrinho, em vez de estarem misturados com os espectadores reais, criando-se, assim, vários efeitos. 0 mais imediato é o da distanciação, pois os espectadores reais estão explicitamente obrigados a ver-se a si próprios no seu papel de voyeurs. Outro é de tipo lúdico-iconográfico, porque os espectadores reais estão convidados também a reconhecer-se como parte integrante do "jogo dos homens", pois afinal é como se estivessem a olhar para um dos "teatrinhos" da colecção do Museu do Teatro, mais ou menos cientes do facto de serem simultaneamente actores no palco da vida. Mas atenção: um dos lustres da plateia "improvisada" no palco está preso por uma "gaiola" de madeira, que evoca a caixa onde será guardado uma vez acabada a função, reiterando-se quer a necessidade de distanciação quer as componentes históricas ligadas a este texto e às suas encenações actuais, visiveis, por exemplo, nos figurinos que estabelecem pontes entre várias épocas. Neste sentido, a luxuosa e solene encenação de Ronconi de Questa sera si recita a soggetto, apresentada neste mesmo palco no âmbito do Festival dos Cem Dias de 1998, foi mais historicista, decorrendo da predilecção do encenador por um certo barroquismo cénico.

Outro momento admirável e eloquente nesta recente montagem portuguesa é a cena da ida ao teatro, em que os actores, que encarnam as suas personagens, estão nuns camarotes e olham para um espectáculo fictício, projectado num ecrã colocado no camarote real, enquanto são vistos pelos espectadores reais, que olham para a dupla realidade / ficção, do palco e do ecrã, podendo ao mesmo tempo ver-se uns aos outros enquanto deslocam o olhar do palco para o camarote e vice-versa. E verso e reverso estão subjacentes, de forma tácita e implícita, quando o teatro lírico é convocado no teatro dramático, num percurso inverso à sua génese, porque esses melodramas - de que - antes de adquirirem a forma operática já foram dramas. Assim, a citação de // trovatore (1852) musicado por Giuseppe Verdi com libreto de Salvatore Cammarano, remete para o facto de esta ópera ser uma variante do drama romântico El trovador (1836), de Antonio Garcia Gutiérrez ${ }^{1}$. E quanto à projecção de La forza del destino (1862), ainda de Verdi, na gravação cinematográfica da produção do Teatro San Carlo di Napoli, de 1958, com Renata Tebaldi, Franco Corelli, Ettore Bastianini e Boris Christof, entre outros, com direcção de Francesco MolinariPradelli, não será por sua vez uma citação da citação da citação...? Porque o filme reenvia para o espectáculo real (àquela representação), o espectáculo real para o espectáculo virtual (à ópera potencialmente inscrita na partitura de Verdi e no libreto de Francesco Maria Piave), e o espectáculo virtual para outro drama espanhol, Don Álvaro, o La fuerza del sino (1835), de Ángel de Saavedra, que viu enxertado nele, para afinamento do enredo da ópera, uma cena inspirada noutro drama mais antigo, Wallenstein $(1799 / 1800)^{2}$, de Friedrich Schiller.

Qual é, então, o grau de realidade, ou de irrealidade, que se apresenta aos olhos do espectador? Porque este está num teatro, a olhar para actores, que estão a representar simultaneamente o papel de actores e personagens, que por sua vez constroem personagens de teatro que já foram personagens duma novela, que olham para actores / cantores que estão a representar as personagens dum melodrama, que por sua vez já foram personagens dum drama. estamos a ver ou ouvir fragmentos nesta peça, aqui e agora
Esta noite improvisa-se, de Luigi Pirandello, enc. Jorge Silva Melo, Artistas Unidos / Teatro Nacional D. Maria II, 2009 (Silvia Filipe, Pedro Lacerda, Victor Gonçalves, John Romão, António Simão, Sara Belo e Luís Godinho), fot. Jorge Gonçalves.

${ }^{1}$ Outro drama de Gutiérrez, Simón Bocanegra (1843), está na génese do Simon Boccanegra verdiano, de que existem dois libretos: o primeiro (1857) de Francesco Maria Piave; o segundo (1881) de Arrigo Boito, que reviu o texto de Piave a pedido de Verdi, que queria testar o talento do libretista / compositor a quem pedirá mais tarde os libretos de Otello (1889) e Falstaff (1893). 


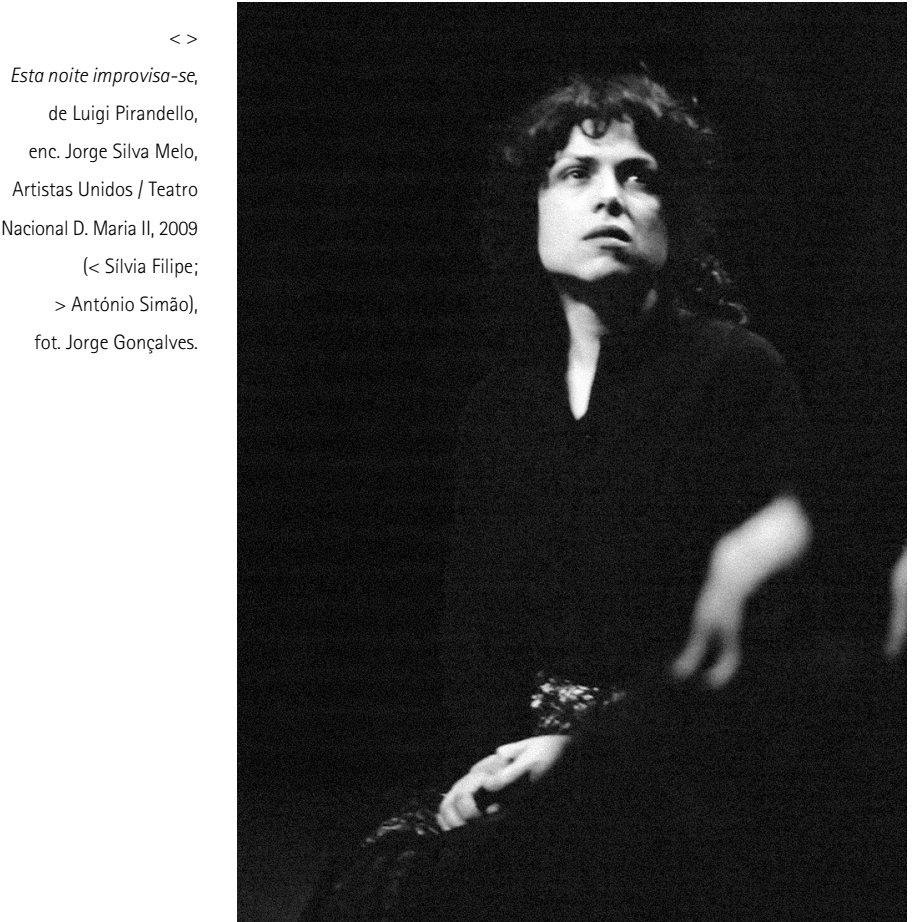

É evidente que o grau de irrealismo do cinema é maior do que o do teatro, não apenas porque Ihe falta a vibração do contacto e a dimensão de verdade que é apanágio do teatro, mas também por propor uma realidade diferida, imutável e estática, que se repete sempre igual, tal como foi capturada no momento em que ficou fixada na película sendo não a forma em movimento, como Pirandello entendia que fosse o teatro, mas movimento sem forma, reflexo dum instante, imagem e reflexo do olhar que os apreendeu para os fixar subjectivamente, e que foram subjectivamente recebidos pelo olhar do espectador final a quem chega um reflexo do reflexo.

Dito por outras palavras, o dramaturgo não gostava de cinema, e não apenas por ver nele um mero meio técnico de reprodução da realidade, mecânico e limitado desprovido duma alma capaz de tocar (ou comungar com outra alma), vocacionado para fins documentais e diversivos, mas também, e talvez como consequência desse pressuposto, pelo facto de o considerar desprovido de qualidades artísticas e de possibilidades estéticas. Contudo, isso não o impede de inserir na sua peça essa cena que propicia a leitura da mise en abîme dos múltiplos olhares em simultâneo, que aliás torna mais explícitas as posições por ele defendidas, com a indicação precisa do filme a projectar, que devia estar sincronizado com uma grafonola que reproduzia a música (o cinema falado ou sonoro estava a dar os seus primeiros passos),

proporcionando ao espectador a comparação entre teatro e cinema (e muito se discutia na altura sobre a questão de o cinema decretar o fim do teatro, tal como no século anterior se desenvolveu a diatribe acerca de a fotografia poder suplantar a pintura): "o final do primeiro acto de um velho melodrama italiano, La forza del destino, ou II ballo in maschera ou qualquer outro sob a condição de que se faça a projecção sincrónica" (Pirandello 1974: 87) Mas "qualquer outro" era a terceira opção. A primeira surge como reiteração da escolha da ópera que, na novela Leonora, addio! (no lugar do Trovador da peça) ia ser

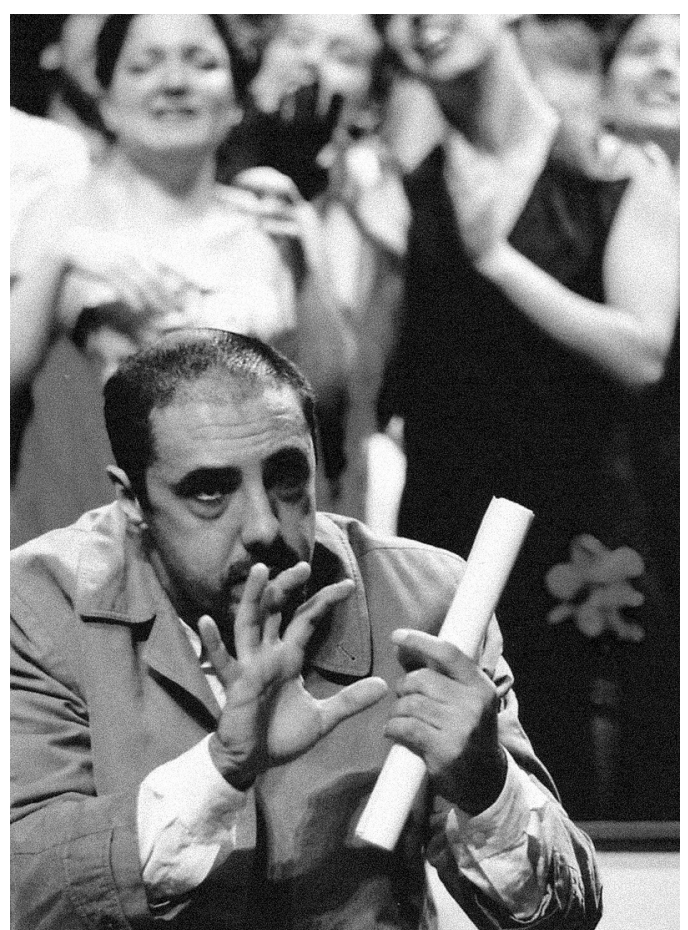

representada no teatro da cidade em que Mommina estava encarcerada, aludindo assim à trágica fatalidade do destino dela, que porém morre (como na peça) cantando as desesperadas palavras com que Manrico se despede de Leonora e da vida (Pirandello 1910: 4; 1974: 209). Quanto à segunda opção, reforça alguns dos temas centrais da peça, como as dicotomias verdade / mentira, ser / parecer autenticidade / simulação.

Aos casos já referidos, some-se mais um: a citação de outra ópera, trauteada por Nené no final do primeiro acto: Carmen (1875) de Georges Bizet, com libreto de Henri Meilhac e Ludovic Halévy, baseada na novela homónima (1845) de Prosper Mérimée, cuja heroina reivindica para si o direito à livre escolha no amor, isto é, pratica um comportamento anti-conformista e em contraste com a moral corrente, tal como acontece na casa de Dona Inácia. Em suma, a forte presença referencial dos dramas e melodramas românticos não são apenas hábil jogo intelectual, intertextual e erudito, do autor, mas antes contribui para intensificar os sentidos denotativos e conotativos por ele atribuidos ao enredo e às personagens.

Jorge Silva Melo, pelo seu lado, é também cineasta, dai que, ao escolher Parlami d'amore Mariü (1932) para a sua cantora de cabaret, substituindo a música de jazz proposta por Pirandello, faz uma mise en abîmesuplementar que é simultaneamente uma homenagem ao cinema. De facto, essa canção, com texto de Ennio Neri e música de Cesare Andrea Bixio, foi escrita e composta para Vittorio De Sica, que a cantou no filme Gli uomini, che mascalzoni! (1932), onde este último entrou como actor, dirigido por Mario Camerini. 0 filme, e especialmente a canção, tiveram um êxito estrondoso. Essas notas correram o mundo pela voz de tenores e intérpretes de excepção e encarnaram o espírito duma latinidade quase piegas, nostálgica e sentimental, hipócrita, medíocre ou ambivalente, dividida por valores e comportamentos contraditórios. Veja-se, a este respeito e a título exemplificativo, a irresistivel comicidade (e mordacidade) da cena da procissão seguida 
pela cena da canção, que acaba por denunciar a obscena convivência de (ou conivência entre) beatice e "putice". As mesmas que são praticadas em casa de D. Inácia sob a bênção dela e sob a indiferença de "Sampognetta", que escolhe $o$ alheamento no trabalho e no cabaret. E como ficarmos indiferentes ao patético e à patetice da cena despojada do candeeiro, quando o homem olha para improváveis estrelas errantes, num enlevo poético que o leva à ignorância do escárnio social e à provável sedução da evasão e dispersão no cosmos? Um desejo de ir de fuga em fuga, em direcção a uma fuga da realidade maior ou até absoluta. Da casa ao cabaret, do cabaret à rua, da rua para o universo, num alargamento progressivo do espaço onde viver e morrer, numa espécie de mise en abîme ao contrário, como que ansiando pelo resgate da pequenez humana, pela sua dissolvência na imensidão do infinito.

Voltando à inquietante e saborosa ambiguidade da multiplicidade dos planos de realidade propostos: no intervalo, quem é que fala quando D. Inácia se refere à gente da sua terra, onde tudo é uma grande "porcaria", designando-a como povoada por "idiotas"? A personagem D. Inácia? A actriz Lia Gama? 0 autor Luigi Pirandello? 0 encenador Hinkfuss? 0 encenador Jorge Silva Melo? E a terra é a da Sicilia, de Portugal, das duas, ou do mundo em geral? Sim, porque afinal quando a dor de dentes ataca a mesma D. Inácia, a Nossa Senhora a quem ela dirige as suas preces é a portuguesissima Nossa Senhora de Fátima, que mal apareceu logo se internacionalizou. E a voz off do encenador que, no começo do espectáculo, lê a didascália que abre a peça, é a do autor do texto ou a do autor do espectáculo? Remete para o corpus narrativo da obra de Pirandello, no qual está enraizado muito do seu corpus dramático, ou é um vago apontamento brechtiano para alertar o espectador sobre a ficção da realidade a que está prestes a assistir? Ou ainda, nesta senda, uma homenagem a Bertolt Brecht e um apontamento de fusão entre este e Pirandello?

A isto acresça-se que ocorreu a feliz casualidade (para mim) de eu assistir ao espectáculo nos dias 27 de Março e 4 de Abril, podendo, assim, presenciar dois eventos distintos e inesperados. No dia 27 de Março, Dia Mundial do Teatro, no fim do espectáculo o encenador Jorge Silva Melo subiu ao palco para ler a mensagem deste ano, assinada por Augusto Boal, tornando evidente a coincidência dos seus pensamentos sobre a função da arte e sobre a necessidade inquestionável de o fingimento (no teatro) ser uma forma de verdade superior, sem máscaras, apta para desocultar as mentiras da realidade. No dia 4 de Abril, no momento do intervalo, a (auto)ironia já presente no espectáculo atingiu a genialidade quando Jorge Silva Melo (o encenador real) apareceu para convidar o público a escolher entre deixar a sala ou deixar-se ficar nas poltronas, tal como fazia o Dr. Hinkfuss (o encenador fictício, a criatura do autor, a paródia de Max Reinhardt, o actor António Simão), dizendo "podem escolher, como na vida". Nesse momento, o encenador real aceitou ser criatura do criador, desmistificando-se a ele próprio e ao seu papel, colocando-se ao lado e no mesmo plano dos seus actores. E não era a ideia dum teatro "sem Deus sem chefe" um dos lemas que presidiram a constituição dos Artistas Unidos? E o repúdio do encenador reivindicado pelo núcleo de actores que fundaram a companhia, bem como o facto de Jorge Silva Melo não se assumir como encenador e demiurgo dos Artistas Unidos, não terão algum parentesco com a revolta das personagens pirandellianas, que não aceitam ser títeres, ora do autor, ora do encenador, reclamando plena autonomia, vida verdadeira, liberdade incondicional de escolher?

Para além de todas as elucubrações e ilações, contudo, sobressaiu de modo inequívoco outra qualidade intrínseca deste espectáculo: a efervescência lúdica, contagiante e festiva do teatro, conseguindo transmitir o genuíno prazer do jogo pelo jogo, tal como fazem as crianças quando brincam "a sério", construindo uma ficção experimentada como pura realidade. E configurou-se também como um espectáculo de perguntas e de hipóteses, de passagem pelos vários registos da comédia, da farsa, do drama e do melodrama, mostrando-nos o desembocar da comédia burguesa na fragmentação modernista da personalidade, as tensões entre a máscara e o rosto congregadas em palco pelo teatro do grotesco, a denúncia das convenções sociais hipócritas e a consequente vontade de afirmação individual. Não se trata do prevalecer do indivíduo sobre a sociedade, como se do surto duma ideologia individualista se tratasse, mas antes do desejo de expressão mais autêntica do ser, que deveria suplantar a falsidade da aparência e das convenções sociais. Porque as duas instâncias - a da interacção social e a do recolhimento intimista - estão presentes nesta peça, mostrando-se na progressão e transição de uma cena para a outra, da monumental partitura coral (Coelho 2009: 9) de toda a primeira parte até ao soberbo "a solo" final de Mommina (Silvia Filipe). E se outras figuras principais tiveram intérpretes de excepção, especialmente os muito experientes Lia Gama e Cândido Ferreira, os mais novos António Simão e Pedro Lacerda também estiveram à altura do empreendimento (mais descontraido o primeiro, concentrado numa tensão pronta para explodir o segundo). Refira-se de passagem que talvez fosse dispensável a opção de Hinkfuss, vista a estridência entre a altura do actor e a descrição do encenador feita pelo autor, ser manifestamente ridiculizado e diminuido aparecendo quase sempre de joelhos. Era talvez desnecessário, porque tal como podiamos imaginar as paredes que cercavam Mommina num espaço despido e de iluminação esbatida, já víamos a pequenez artística desse encenador retratado por Pirandello que, ao mesmo tempo, sugere tácita e implicitamente que também a altura do autor é relativa, pois as personagens reivindicam vida própria, escapam à vontade do criador, mas sem actores são letra morta. E foi evidente o entendimento do teatro como generoso trabalho colectivo no desempenho geral de todo o elenco, amalgamado e coeso, que deixou transitar 
Esta noite improvisa-se, de Luigi Pirandello, enc. Jorge Silva Melo, Artistas Unidos / Teatro Nacional D. Maria Il, 2009

(Pedro Lacerda, Alexandre Ferreira, Cecilia Henriques,

Silvia Filipe, Victor Gonçalves, Andreia Bento, Lia Gama, John Romão, Sara Belo, Pedro Luzindro

e João Meireles), fot. Jorge Gonçalves.

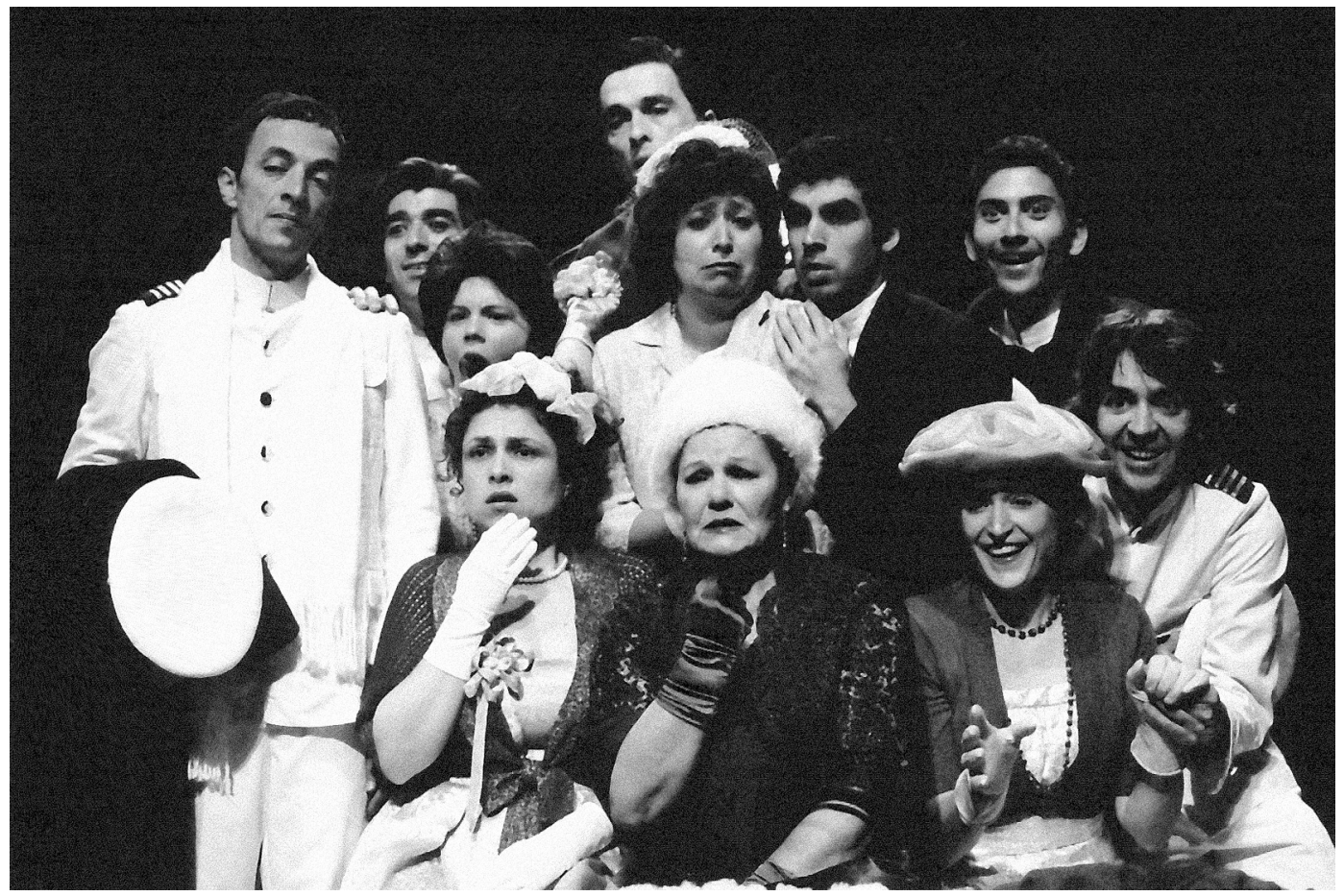

do palco - ou dos outros espaços que foram ocupando - para o público a ideia central desta encenação: o protagonismo absoluto do jogo. Mas nunca inocente nem gratuito, antes pelo contrário, porque Pirandello partiu o brinquedo para nos mostrar como funciona por dentro e as emoções que pode suscitar.

A tradução de Osório Mateus e Luis Miguel Cintra é muito feliz e, atentissima na escolha das exactas correspondências lexicais e semânticas, transmite toda a vivacidade dos diálogos originais. Não faltam, na edição de 1974, algumas (poucas) liberdades interpretativas, que resultam convincentes por procederem claramente de inferências dos contextos e diálogos, mas houve em certos casos leves ajustes na edição de 2009, revista por José Maria Vieira Mendes e Jorge Silva Melo.

Vejamos alguns exemplos. A alcunha "Sampognetta" (Pirandello 1941: 266; literalmente "gaita de foles") foi traduzida por "o búzio" (Pirandello 1974: 46) e, posteriormente omissa na versão impressa (Pirandello 2009: 175), é recuperada no espectáculo. "Tu hai le traveggole" (Pirandello 1941: 290; literalmente "ter a vista ofuscada") surgiu como "Tu estás é grosso" (Pirandello 1974: 78) e foi rectificado com "Estás mas é a ver a dobrar" (Pirandello 2009: 195). "Alla porta i disturbatori" (Pirandello 1941: 299; literalmente "importunos, perturbadores") ficou simplesmente "Rua com elas" (Pirandello 1974: 90), onde o referente circunscreve os elementos molestos às personagens femininas, enquanto a nova versão "Rua com eles" (Pirandello 2009: 198) restaura o referente inicial genérico que incluia a totalidade do grupo.

Todavia, escaparam ao crivo da revisão da 1. ${ }^{\text {a }}$ /ou da 2. edição portuguesa pequenos lapsos pouco relevantes numa avaliação global. Veja-se a irregularidade na uniformização das formas de tratamento com que as filhas se dirigem aos pais (neste caso, justamente devido à época e às convenções da língua de chegada, à 2. ${ }^{\text {a pessoa }}$

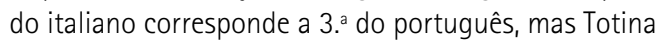
acaba por empregar o mais familiar "tu": "Oh Dio, papà!
Che t'hanno fatto?" [Pirandello 1941: 292], surge como "Oh, meu Deus! Papá, o que foi que te fizeram?" [Pirandello 1974: 80; Pirandello 2009: 193]). Porém, a fala de D. Inácia que, referindo-se ao marido (o senhor Palmiro, no original "ingegnere minerario" [Pirandello 1941: 266], em português mais genericamente "agente técnico de minas" [Pirandello 1974: 46; Pirandello 2009: 175]), informa os presentes que "Domani si deve alzar presto per andare alla zolfara" (Pirandello 1941: 295), isto é, à mina de enxofre onde trabalha, que foi inicialmente transposta como "tem que se levantar cedo para ir para a vinha" (Pirandello 1974: 85) e recentemente corrigido com "tem que se levantar cedo para ir para a mina" (Pirandello 2009: 195). Meros pormenores e/ou lapsos de somenos importância, que não comprometem a excelência do resultado no seu todo.

\section{Referências bibliográficas}

AA.W. (2009), "Programa" do espectáculo Esta noite improvisa-se, Lisboa, Artistas Unidos / Teatro Nacional D. Maria II, Março-Abril.

COELHO, Rui Pina (2009), "Nesta crítica, improvisa-se", Público, suplemento P2, 9 de Março, p. 9.

PIRANDELLO, Luigi ([1910]), "Leonora, addio!", in Novelle per un anno: /I viaggio ([1928]), www.pirandelloweb.com/novelle/1928_il_viaggio/ il_viaggio_13_leonora_addio.htm\#

-- (1941), "Questa sera si recita a soggetto", in Maschere nude, Verona, Casa Editrice A. Mondadori, pp. 247-387.

-- (1974), Esta noite improvisa-se, trad. J.A. Osório Mateus e Luis Miguel Cintra, Lisboa, Editorial Estampa.

-- (2009), Esta noite improvisa-se, in Seis personagens à procura de autor / Para cada um a sua verdade / Esta noite improvisa-se, trad. Mário Feliciano e Fernando José Oliveira, Natércia Freire e Maria da Graça Freire, J.A. Osório Mateus e Luis Miguel Cintra, trad. revistas por José Maria Vieira Mendes e Jorge Silva Melo, Lisboa, Artistas Unidos / Livros Cotovia, Livrinhos de Teatro n. 36 , "Os clássicos".

ROMEI, Giovanna (1993), Luigi Pirandello: la trilogia del teatro nel teatro, Roma, Teatro di Roma. 